\title{
Influence of Taylor cone size on droplet generation in an indium liquid metal ion source
}

Space Propulsion, ARC Seibersdorf research, 2444 Seibersdorf, Austria

\section{Published online: 4 August 2005 • (C) Springer-Verlag 2005}

Unfortunately, equation (9) and Fig. 5 of this article printed with errors. The correct form of equation (9) is given below together with the corresponding Fig. 5.

$$
\begin{aligned}
& I \leq I_{\mathrm{c}} \eta=100 \% \\
& I \geq I_{\mathrm{c}} \begin{cases}\eta=\left(\frac{I}{I_{\mathrm{c}}}\right)^{-0.15 R+0.0698} & R<5.8 \mu \mathrm{m} \\
\eta=\left(\frac{I}{I_{c}}\right)^{-0.0028 R-0.88} & R \geq 5.8 \mu \mathrm{m}\end{cases}
\end{aligned}
$$

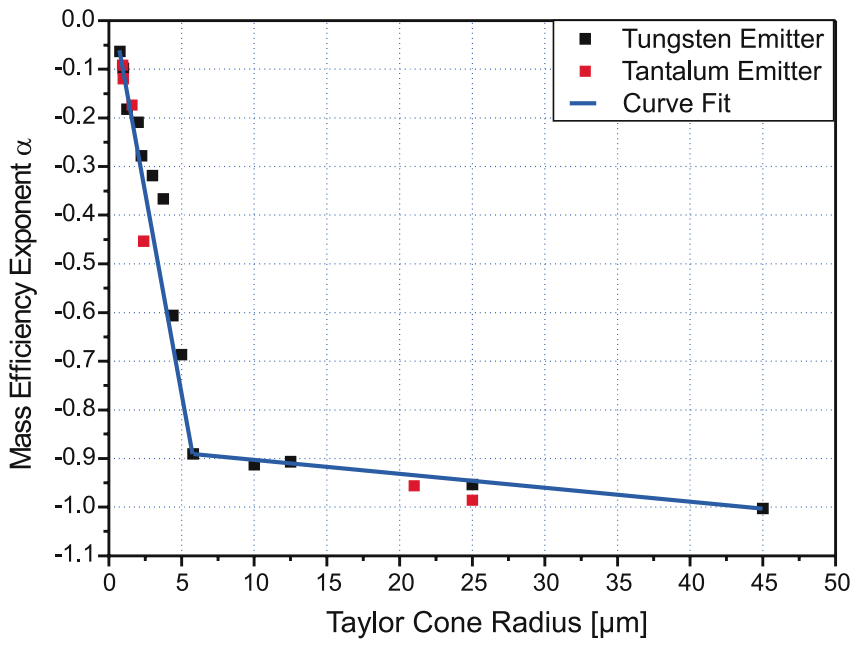

FIGURE 5 Mass efficiency exponent versus Taylor cone radius
Appl. Phys. A

DOI 10.1007/s00339-005-3207-3

Published online: 2 March 2005

Head of Space Propulsion,

Fax: +43-50550-3366, E-mail: martin.tajmar@arcs.ac.at The online version of the original article can be found at http://dx.doi.org/10.1007/s00339-004-3014-x 